\title{
ASSESSMENT OF THE ADAPTIVE PERSONAL POTENTIAL OF THE PATIENTS WITH PARANOID SCHIZOPHRENIA
}

DOI: 10.36740/WLek202007116

\author{
Olena F. Mruh \\ NATIONAL PIROGOV MEMORIAL MEDICAL UNIVERSITY, VINNYTSIA, UKRAINE
}

\begin{abstract}
The aim: assessment of the patients with paranoid schizophrenia adaptive personal potential.

Materials and methods: Clinical-anamnestic method, questionnaires for determining "structural ego-states" by J. Hey, of the "drivers" by M. Cox, of the "personal adaptations" by Joines, for determining the "crisis moments of development" by J.I. Clark, statistical analysis of the results data.

164 patients with a newly diagnosed and episodic paranoid schizophrenia took part in this study.

Results: "Passive behavior" serves as a typical door for contact by $88 \%$ of the patients. According to the methodologies of determination of the "drivers" the following results were received:"make the others happy" - 28\%, "be strong" - 76\%, "be perfect" - 65\%, "make efforts" - 5\% "hurry up" - 15\%; of "crisis moments in development" determination, $61 \%$ were determined as "stuck" in the 1st stage of the development. By $74 \%$, there was a "script prohibition", "do not be close." By $72 \%$ there was a "prohibition" "do not have feelings". The prevailing combinations of the "personal adaptations" were "schizoid" (92\%) and "paranoid" (81\%).

Conclusions: schizophrenia can be viewed as a defensive reaction. The "ego- states of the controlling parent" and "adaptive child" dominate. The dominant "drivers" are "make the others happy" and "be strong." Typical "script prohibitions" are "do not be close," "do not feel,"'do not think" and "do not be healthy." The typical "personal adaptations" of the patients are "schizoid" and "paranoic".
\end{abstract}

KEY WORDS: personality structure, transactional analysis, psychosocial rehabilitation

Wiad Lek. 2020;73(7):1391-1396

\section{INTRODUCTION}

There are important changes in the world psychiatry associated with understanding and awareness of the significant role of rehabilitation in the complex treatment of the mental illnesses of the schizophrenic spectrum. The most important for such patients are increase in neurocognitive deficit and complex psychological problems in the family, associated with the risk of its breakdown, stigmatization by the society with the social "displacement" of the patient and overall decline in the quality of his/her life [1].

The practicing psychiatrists have the necessity of awareness the importance of including a complex combination of psychopharmacotherapy, psychotherapeutic and social rehabilitation methods approaches in the treatment program of schizophrenia at all stages of the therapy. These approaches were included in the clinical protocols for providing medical care to the patients with schizophrenia $[2,3,4,5]$. The transactional analysis (TA) found its place in the system of rehabilitation measures $[6,7]$.

The pathodynamic component of the adaptive personality potential of the patients with schizophrenia includes such characteristics as the rate of progression, the relevance of psychopathological rueful feelings, the ratio of the positive and deficient symptoms, the phenomena of disorganization of the mental processes and mechanisms for compensating disorders at the clinical-psycho-pathological level [8].
The problem of psychotherapy of the patients with schizophrenia is relevant to the modern society, which seeks to socialize and ensure the adequate standard of living for everyone. The transactional analysis proved to be an effective method for psychotherapy of such patients, but it lacks theoretically grounded and statistically confirmed data on the characteristics of the structure and personality development, characteristic behavioral patterns, components of the internal picture of the disease by schizophrenia, necessary to improve the system of the effective psychotherapy. From the perspective of the transactional analysis, the patient is the subject of psychotherapy in the sequential development of the structure of his/her personality structure. Of course, such an integrative approach is a definite novelty compared with the discrete-descriptive diagnostic approach, which due to well-known historical and social circumstances is ingrained in the domestic psychiatry and clinical practice.

\section{THE AIM}

Assessment of the adaptive personal potential of the patients with paranoid schizophrenia. The object of this study was to determine the structure of the personality as a component of the adaptive personal potential of the patients with the paranoid form of schizophrenia. The subject of the study were the factors of forming the internal picture 
of the disease by the patients with the paranoid form of schizophrenia. The task of the study was to investigate the factors that form the internal picture of the disease in the paranoid form of schizophrenia using psychodiagnostic methods to determine the characteristics of the personality structure.

\section{MATERIALS AND METHODS}

Theoretical analysis of the current state of the problem under study, clinical and anamnestic method, questionnaire for determining "structural ego-states" by Julia Hey, questionnaire of the "drivers" by Mary Cox, questionnaire of the "personal adaptations" by Joines, questionnaire for determining the "crisis moments of development" by Jean Isily Clark, statistical analysis of the results data. In the course of the study, the patients with CG (control group) No.2 and SG (study group) No.2 received psychotherapeutic correction in the form of group psychotherapy using the transactional analysis three times a week. According to the conclusions of the examination of the ethics committee of the university during the course of this study, all the main provisions of biomedical ethics were observed.

\section{RESULTS}

64 patients with a first-time diagnosis of paranoid schizophrenia and paranoid schizophrenia with episodic course took part in this study, in which 91 - women and 73 men, the average age of the patients made up 29,25 $\pm 13,5$ years, the total number of the patients with the diagnosis "paranoid schizophrenia" - 118, with the diagnosis "acute polymorphic psychotic disorder with symptoms of schizophrenia" - 46 patients, which by re-hospitalization, had the diagnosis of "paranoid schizophrenia", the average illness duration $-2,7 \pm 2,1$ years.

There were 4 groups of patients formed, depending on the received anti-psychotic and psychotherapy: the study group No.1 (SG) included the patients who received anti-psychotic therapy with atypical anti-psychotics with pronounced sedative action (quetiapine), with activating action (aripiprazol, risperidone, amisulpride, sertindol); the study group No.2 (SG + PC) (psychotherapeutic correction) included the patients who received anti-psychotic therapy with typical anti-psychotics with pronounced sedative action (quetiapine) and with activating action (aripiprazol, risperidone, amisulpride, sertindol) and psychotherapeutic correction in the form of group therapy using the transactional analysis; the control group No.1 (CG) included the patients who received anti-psychotic therapy with atypical anti-psychotics with pronounced sedative action (chlorpromazine, levomepromazine, flufenazine, flupentixol, zuclopentixol) and with activating action (butyrophenone, trifluoperazine, thioridazine); control group No.2 (CG + PC) included patients receiving anti-psychotic treatment by the typical anti-psychotics with pronounced sedative action (chlorpromazine, levomepromazine, flufenazine, flupentixol, zuclopentixol) and with activating action (butyrophenone, trifluoperazine, thioridazine) and psychotherapeutic correction in the form of group therapy using the transactional analysis.

In the course of the examination, the following dominant functional "ego-states" were identified by the patients under study Fig. 115 (60\%) patients of CG + PC and 28 (68\%) patients of SG + PC had "ego-state of the controlling parent"; $0 \%$ of the patients of CG + PC and $0 \%$ of the patients of SG + PC - "ego-state of the caring parent", 5 (12\%) patients of CG + PC and $5(12 \%)$ patients of SG + PC - "ego-state of the adult"; $5(20 \%)$ patients of CG + PC and $8(20 \%)$ patients of SG + PC - "ego-state of the adaptive child"; 0\% of the patients of CG + PC and $0 \%$ of the patients of SG + PC - "ego-state of the free child".

The typical doors "for contact", by Paul Ware, were assigned as "passive behavior" by $22(88 \%)$ patients of CG + PC and $36(87 \%)$ patients of SG + PC.

3 patients (12\%) of CG + PC and 5 (13\%) patients of SG + PC make contact with the outside world through its understanding.

According to the test methods of determination of the leading "drivers" by Mary Cox by the persons under study the following combinations of the behavioral partners or "drivers" were determined Fig. 2: "make others happy" by 7 patients (27\%) of CG + PC and 12 (28\%) of SG + PC, "be strong" by $18(72 \%)$ of CG + PC and $32(76 \%)$ of SG + PC, "be perfect" by 15 (60\%) of CG + PC and $27(65 \%)$ of SG + PC , "make efforts" by 2 (6\%) of CG + PC and $2(5 \%)$ of SG + PC and "hurry up" by $3(12 \%)$ of CG + PC and $6(15 \%)$ of SG + PC.

During the conducted methods for assigning the "crisis moments of the development" by Jean Isily Clark by 17 (67\%) of the persons of CG + PC and by 25 (61\%) of SG + PC under study there was "stuck" on the 1st stage of development. By 18 (71\%) patients of CG + PC, and by $30(74 \%)$ of SG + PC, there was a "script prohibition" "do not be close" found.

By 17 (67\%) of the examined patients of CG + PC and by $29(72 \%)$ of SG + PC the "prohibition" "do not have your feelings" was revealed. The "prohibition" "do not think" revealed by 14 (55\%) patients of CG + PC and also by 20 patients (48\%) of SG + PC. By 14 (55\%) patients of CG + PC and by 25 (61\%) of SG + PC, the "prohibition" "do not be healthy" was revealed that they materialized getting sick with schizophrenia.

According to the criteria for determination of the "personalized adaptations" the most prevalent combinations of patients' "personalized adaptations" were determined: "schizoid" - by 21 (85\%) of CG + PC and by $38(92 \%)$ of SG + PC and "paranoid" - by $19(76 \%)$ of CG + PC and by $33(81 \%)$ of SG + PC.

\section{DISCUSSION}

The negative manifestations of attention, which were called "strokes" by Berne, are the reflection of the negative "parent ego-state" of the parenteral figures and therefore form the negative parent introject by the persons under study. Thus, 

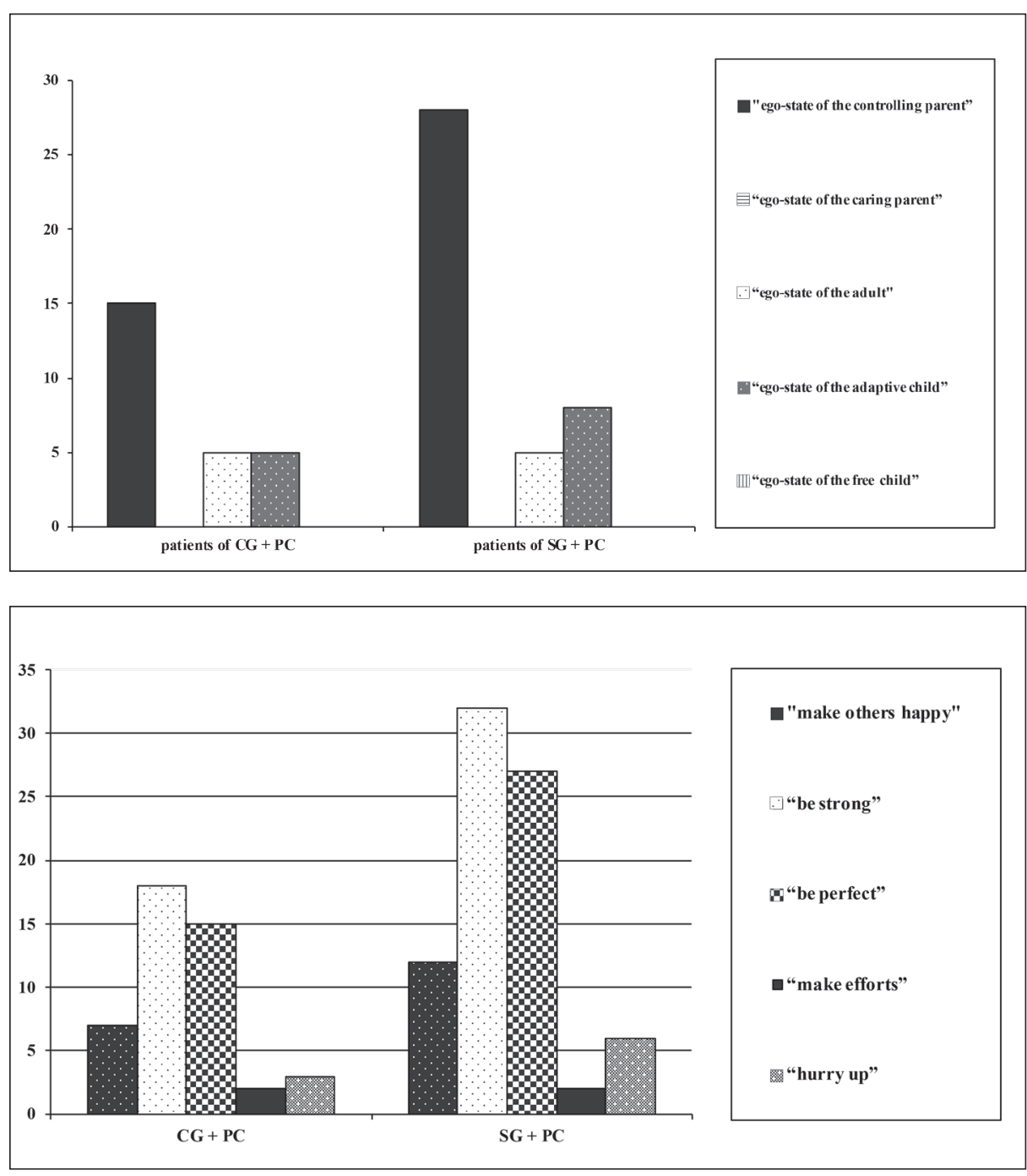

Fig. 1. Results of determining the dominant functional "ego-states" by the patients with paranoid schizophrenia under study.
Fig. 2. Results of determining the leading "drivers". in this group of the persons under study, the contamination of the "parent ego-state" and the disabled "child ego-state" are determined.

These individuals are inclined to criticize themselves from the "parent ego-state" and use the defense mechanism of "escape" in response to their "child ego-state". The more they "escape", the more the "parent ego-state" criticizes them. Thus, the individual is stuck in his/her negative feelings. This structure is formed on the early oral stage, when basic needs remain unsatisfied [8]. According to this hypothesis, their parents were excessively immersed in their own emotions, and children made an early decision not to speak about their needs in the "hope" that the parents would be satisfied and feel so good to take care of the children themselves [7].

Presence of the "adult ego-state" by the persons under study indicates a sufficient level of awareness of themselves and their rueful feelings. Thus, this group of patients has favorable prerequisites for conducting effective psychotherapy.

Thus, it is determined that the "ego-states of the adaptive child" and "controlling parent" dominate in the persons under study. The "ego-state of the caring parent" was not defined by any patient. These data correlate with the results obtained in determining the dominant structural "egostates". Any structural "ego-state" can manifest itself in any functional "ego-state", as a result of which the "parent egostate" dominating in the structure of personality during regress manifests itself functionally in the "ego-state of the adaptive child" and "controlling parent" [6]. The functional "ego-state of the adaptive child" directly reflects the structure and provides adaptive behavior. Since the persons under study were subject to violence in childhood, a solution such as a "survival strategy" was expedient at that time, and this form of behavior was an opportunity to adapt to the environment in order to save the own life. But in the present time, dominance of the "ego state of the adaptive child" is no longer relevant and causes social maladjustment of these patients. The functional "ego-state of the controlling parent" directly reflects the parent introjects. The purpose of the "controlling parent" is to dominate, criticize, and devalue the others [9]. The persons under study absorbed these characteristics of their real parents and formed rigid introjects. "Ego-state of the caring parent" was not observed by any of the persons under study. This result can be explained by the fact that the persons under study did not receive enough care and support 
from their parents and therefore did not form an introject of the positive "caring parent". According to the clinical interview, the persons under study received $45 \%$ more physical negative manifestations of attention (for example, physical punishment) than positive ones (for example, kisses, hugs), and $60 \%$ more negative verbal manifestations of attention (for example, criticism) than positive verbal ones.

"Passive behavior as the escape from the real interaction" is the main way for such people to respond to the world around them. The resource for such people is awareness of their "escape" through action, which will result in restoration of the internal contact with the emotional sphere from which patients with schizophrenia are dissociated. Passive behavior is the manifestation of the process of dissociation - internal alienation from unpleasant emotions. They put much of their energy into their behavior. You must begin to act together with them to establish the contact. These individuals do not feel safe enough to demonstrate their needs and feelings. To get out of their typical state, they must involve their thinking process, but instead of thinking about their real needs and their satisfaction, they are inclined to fantasize a lot and replace reality with fantasy. Thinking is an internal process for them which they externalize a little. If you give positive support to such individuals, they begin to externalize their thinking process and come closer to reality.

The results that 3 patients (12\%) of CG + PC and 5 (13\%) patients of SG + PC make contact with the outside world through its understanding correlate with those obtained below about the leading "drivers", namely with the dominance of the "driver" "be perfect". For such individuals, manifestations of attention about the clarity of their thinking are important, and feelings are a zone of difficulty. To restore the contact with the feelings, they need to learn to test their ideas about the thoughts and feelings of others from the "ego-state of the caring parent". These individuals do not feel safe enough and believe that they should control every detail, so they think everything over in detail, are skeptical about everything around. They often distort others as they project their own perception of danger.

Based on the results of the leading "drivers" determination, it is possible to determine that the behavioral pattern "be strong" plays a significant role in formation of the internal picture of the disease of the persons under study. It manifests itself by overly restrained behavior, alienation from the own feelings, confidence in the own strength and self possession. This "driver" ensures functioning of the personality after dissociation and enables the individual not to come into contact with his/her rueful feelings, which seem threatening and destructive to him/her. In order to "please" their parents, such individuals try to "be strong" without having needs and equating the concepts of "being strong" and "being good". Their parents ignored their needs, as a result of which they made an early childhood decision "I would be really good if I didn't have needs at all." The driver "make others happy" is the manifestation of the functional "ego-state of the adaptive child" and provides adaptation behavior [10]. Thus, individuals who have been exposed to the traumatic influence of the parental figures implement their old script decision to adapt in order to avoid additional negative incentives.

From 0 to 6 months the main task is "to be". "Prohibitions" that a child can receive at this stage are "do not exist", "do not feel", "do not have needs", "do not be healthy", "do not be close" [11]. Patients with the paranoid schizophrenia are injured at the very early stage of their development, which causes manifestations at all levels of functioning. They are characterized by the basic mistrust, dissociation from their own experiences, disorientation in their own feelings and self-awareness. The basis of these experiences are two basic frustrated needs - in safety and in close contact. These individuals are afraid to let something go out of control and be "unprepared." Such fear arises in early childhood, when a child in reality cannot protect itself from something unexpected happening. Thus, these individuals decided to control themselves, others and keep others at a safe distance.

The patients with "script prohibition" "do not be close" experienced negative manifestations of attention or neglect and rejection by their parents in childhood as a result of which they made the early childhood decision to "emotionally stay away from people in order to avoid negative feelings of abandonment, loneliness and anguish". In order to avoid destructive criticism from their parents, they decided in their childhood "if I control everything, I can prevent all bad things and avoid danger" [11]. The "prohibition" "do not have your feelings" revealed by $67 \%$ of the examined patients of CG + PC and by $72 \%$ of SG + $\mathrm{PC}$ is tightly connected with the decision "do not be close" and it is an internal protection from pain. The "prohibition" "do not think" revealed by 55\% patients of CG + $\mathrm{PC}$ and also by $48 \%$ of SG + PC, is formed from previous "bricks": as a person is dissociated from the signals of his/ her own body - sensations and feelings, his/her thoughts are based on his/her own fantasies, and not on real facts. This "prohibition" is manifested by excessive day-dreaming, inability to analyze data about the world around us and to distinguish our fantasies from reality. The "prohibition" "do not be healthy" revealed by $55 \%$ of the patients of CG + PC and by $61 \%$ of SG + PC can be explained that they materialized getting sick with schizophrenia.

For the "schizoid" the contamination of the "parental ego-state" is typical. A typical functional "ego-state" is the "ego-state of the adaptive child." These features of functional and structural "ego-states" were identified by the patients under study. A characteristic "life position" is "I -, You -", which corresponds to the criteria of the "personalized adaptation" of the "schizoid" and examination data [12]. The tone is usually smooth and monotonous, mimic and gesticulation are poor. Basic needs include recognition and satisfaction of their needs and feelings. People with such an adaptation avoid problem solution. Relevant "prohibitions" are "do not be healthy", "do not be close", "do not feel", "do not think", which correspond to the examination data. The "door for contacting" the "schizoid" are carried out through behavior, same was determined by the patients under study $[13,14]$. 
For the "paranoic" the "parental contamination" and excluded "child's ego-state" are typical, and the leading functional "ego-state" is the "ego-state of the controlling parent," that corresponds to the data revealed in the patients. The "life position" is "I +, You -", that is the second predominant among the patients. In the situations of significant stress it changes to the position "I -, You -". The monotonous voice, straight and immovable posture are typical. The basic needs include trust and feeling safe. The main "prohibitions" are "do not feel", "do not be close" and "do not trust". The leading "directives" are "be perfect" and "be strong." These characteristics coincide with the data obtained during the patients' examination. The "door for contacting" the "paranoic" is thinking - understanding of thoughts, that leads to understanding of feelings and then to changes in behavior.

Thus, from the point of view of the transactional analysis theory, the schizophrenia-related disorders can be considered as a defensive reaction. Such a personality structure allows to dissociate the "intolerable" part of your own experience and "separate" it from yourself. The schizoid protection occurs when the others do not pay enough attention to the child's needs or react negatively to any manifestation of his/her needs or feelings. As a result, these personalities form the basic existential position "I -, You -", which is formed as a result of receiving such "prohibitions": "do not have feelings, sensations and needs", "do not think", "do not be healthy", "do not live ". The paranoid traits reflect the following aspects of the personality development: an episodic response to the child's needs and the messages like "do not be close" and "do not trust". As a result, he/she gets the idea that "if he/she controls everything, then he/she can prevent all the bad things from happening".

This paper presents a theoretical generalization and practical optimization of the effectiveness of treatment and rehabilitation of patients with paranoid schizophrenia based on the study of features of clinical and psychopathological picture of the disease and the integration of transactional analysis into the complex treatment model to improve adherence to therapeutic recommendations, reduce the time frame of the inpatient phase of therapy and to provide the further reconstruction of the identity of the patient. Established scientific goals have been fully achieved, and the results of this study are completely original. A potential limitation of illustrating the effectiveness of this approach is the fact that, on the one hand, a longer stay of the patient in the hospital causes a significant reduction in the risk of re-hospitalization due to longer support of the patient with psychotherapy counseling, however, on the other hand, may be the trigger factor in the formation of the phenomenon of hospitalism.

\section{CONCLUSIONS}

Patients with paranoid schizophrenia do not trust anyone at an unconscious level (including their organs and thinking based on real facts) and are "forced" to build their own understanding of reality that would satisfy their frustrated need for contact with an important close person (reliable affection pattern), because accepting of the fact that they were rejected by important close people and the awareness of their despair thereof is destructive for them. Thus, schizophrenia-related disorders can be considered as a defensive reaction. "Ego-states of the controlling parent" and "adaptive child" dominate in the patients with paranoid schizophrenia. The absence of the introject of the "ego-state of the caring parent" in the patients with paranoid schizophrenia is caused by a lack of care and support from parental figures in childhood. The patients with paranoid schizophrenia have the prevailing "life position" "I -, You - " as a reflection of basic distrust to the world around, devaluation of themselves and others. The leading "driver" "be strong" by the patients with paranoid schizophrenia provides functioning of the personality after dissociation. The "drivers" "make others happy" and "be strong" - dominating by the patients with paranoid schizophrenia are formed as a result of the psycho-traumatic influence of the "ego-state of the controlling parent" of parental figures and are functional manifestations of the "ego-state of the adaptive child". According to the transactional analysis theory the patients under study did not pass the first stage of the personality development completely that violates the personality formation at the earliest stage and preconditions the pathological manifestations at all the functioning levels. The typical "script prohibitions" of the patients under study are "do not be close", "do not feel", "do not think" and "do not be healthy". The characteristic "personalized adaptations" for the patients with paranoid schizophrenia are "schizoid" and "paranoic".

\section{REFERENCES}

1. Abramov V., Zhigulina I., Ryapolova T. Mediko-social'naya reabilitaciya bol'nyh s psihicheskimi rasstrojstvami [Medical and social rehabilitation of the patients with mental disorders]. Donetsk: Kashtan. 2016. 254255. (In Russian).

2. Abramov V., Putyatin G., Abramov A. Psihicheskij defekt pri shizofrenii i problema gospitalizma [Mental defect in schizophrenia and the problem of hospitalism]. Zhurnal psihiatrii i medicinskoj psihologii. 2015; 1:101-116. (In Russian).

3. Shacberg A.F., Koul J.0., DeBattista C. Rukovodstvo po klinicheskoj psihofarmakologii [Guidelines for Clinical Psychopharmacology]. Moscow: MEDpressinform. 2013. 149-220. (In Russian).

4. Bern E. Igry, v kotorye igrayut lyudi: psihologiya chelovecheskih vzaimootnoshenij. Lyudi, kotorye igrayut v igry: psihologiya chelovecheskoj sud'by [Games that people play: the psychology of human relationships. People who play games: the psychology of human fate]. Moscow: Progress. 2016. 98-165. (In Russian).

5. Mosolov S. Sovremennyj etap razvitiya psihofarmakoterapii. Novye dostizheniya v terapii psihicheskih zabolevanij [The current stage of development of psychopharmacotherapy. New advances in the treatment of mental illnesses]. Moscow: BINOM. 2002. 244-267. (In Russian).

6. Cox M. The relationship between ego state structure and function: a diagrammatic formulation. TAJ. 1999; 29(1):35-46. (In English).

7. Dusay J. Egograms and «Constancy hypothesis». TAJ. 1972;2(3):98-102. (In English). 
8. Dzhojns V., Styuart J. Osnovi trakzakcijnogo analizu [Basics of Transactional Analysis]. Kyiv: FADA, LTD. 2016. 128-135. (In Ukrainian).

9. Gulding M., Gulding R. Psihoterapiya novogo resheniya: teoriya i praktika []. Saint-Petersburg: Piter. 2016. 45-68. (In Russian).

10. Clarkson P. Transactional analysis. Psychotherapy, London: Tavistock, Routledge. 2003. 113-153.

11. Stajner K. Scenarii zhizni lyudej [Life scenarios]. Saint-Petersburg: Piter. 2018. 292-305. (In Russian).

12. Joines V., Stewart I. Personality Adaptations. A new Guide to Human Understanding in Psychotherapy and Counseling, Nottingham, Chapel Hill: Lifespace Publishing. 2016. 75-112.

13. Schiff J.L. The Cathexis reader: transactional analysis treatment of psychosis, New York: Harper and Row, 1975. 47-96.

14. Schiff J.L. Biochemical evidence of cure in schizophrenics. TAJ. 1977; 7(2):178-181.

15. SchiffS. Personality development and symbiosis. TAJ. 1977; 7(4):215239.

16. Wilson E.T. Reparanting schizophrenic youth in a hospital setting. TAJ. 1985; 15(3):211-215.

The article was completed as part of the research work of the Department of Psychiatry, Narcology and Psychotherapy with the Postgraduate Education Course of National Pirogov Memorial Medical University, Vinnytsia, Ukraine "Scientific justification of diagnostic, therapeutic and rehabilitation measures for endogenous and exogenous organic psychotic and nonpsychotic mental disorders" (state registration number 0113U000856).

\section{ORCID and contributionship:}

Olena F. Mruh 0000-0003-3604-1464 ${ }^{A, B, C, D, E, F}$

\section{Conflict of interest:}

The Author declare no conflict of interest.

\section{CORRESPONDING AUTHOR}

\section{Olena F. Mruh}

National Pirogov Memorial Medical University

56 Pirogova st., 21018 Vinnytsia, Ukraine

tel: +380989279398

e-mail: olena.mrug@gmail.com

Received: 10.01 .2020

Accepted: 25.05 .2020

A - Work concept and design, B - Data collection and analysis, C - Responsibility for statistical analysis, D-Writing the article, $\mathbf{E}$-Critical review, $\mathbf{F}$ - Final approval of the article 